\title{
Extracellular Signal-Regulated Kinase Activity in the Entorhinal Cortex Is Necessary for Long-Term Spatial Memory
}

\author{
April E. Hebert and Pramod K. Dash ${ }^{1}$ \\ Department of Neurobiology and Anatomy, The Vivian L. Smith Center for Neurologic Research, The University of Texas Medical School, \\ Houston, Texas 77225, USA
}

\begin{abstract}
Lesion studies have provided evidence that the entorhinal cortex (EC) participates in spatial memory. However, the molecular cascades that underlie memory-associated changes in the EC and its specific role in spatial memory, however, have not been clearly delineated. Recently, it has been shown that activation of extracellular signal-regulated kinase (Erk, a mitogen-activated protein kinase family member) in the dorsal hippocampus is necessary for spatial memory. To examine whether similar mechanisms are used for spatial memory storage in the EC, Erk activity was inhibited after training in the Morris water maze. Bilateral infusion of the mitogen-activated protein kinase kinase inhibitor PD098059 into the EC immediately after training resulted in a memory deficit observed during a retention test performed $48 \mathrm{~h}$ later. This deficit was abolished with pretraining in a different water maze in which animals were able to learn the general task requirements and the appropriate search strategies. The absence of a deficit indicates that Erk activity in the EC may be involved in storing the task requirements or the search strategies. The findings presented in this article are consistent with the idea that the EC is involved in spatial memory and indicate that Erk activity is necessary for memory consolidation in this structure.
\end{abstract}

Clinical and experimental studies indicate that although normal long-term spatial memory is dependent on the hippocampus (O'Keefe et al. 1975; Morris et al. 1982; ZolaMorgan et al. 1986; Press et al. 1989), other cortical structures participate in the long-term storage of these memories (Zola-Morgan and Squire 1990; Kim and Fanselow 1992; Bontempi et al. 1999; Teng and Squire 1999). Specifically, the entorhinal cortex (EC) may be necessary for long-term spatial memory storage. The EC is a major input and output structure for the hippocampus, receiving sensory information from association cortices and sending projections to all hippocampal subfields. Lesions of the EC result in deficits in acquisition and retention in the Morris water and radial arm maze tasks (Holscher and Schmidt 1994; Cho and Jaffard 1995; Nagahara et al. 1995; Galani et al. 1997), as well as retrograde amnesia (Schenk and Morris 1985; Cho et al. 1993, 1995). However, variation in the extent and specificity of lesions and the confounding lesions of passing neuronal fibers have hindered the determination of the exact role of the EC in spatial memory (Hagan et al. 1992; Pouzet et al. 1999; Bannerman et al. 2001). Electrophysiological studies in rats show that the medial EC contains spatially selective cells (Quirk et al. 1992), and that in humans, en-

${ }^{1}$ Corresponding author.

E-MAIL p.dash@uth.tmc.edu; FAX 713-500-0621.

Article and publication are at http://www.learnmem.org/cgi/doi/ $10.1101 / \mathrm{lm} .48502$. torhinal-hippocampal gamma synchronization is correlated with successful, but not unsuccessful, encoding of new memories (Fell et al. 2001). Taken together, these studies indicate that the EC plays an important role in memory processes. However, the molecular mechanisms underlying memory consolidation in the EC are unknown.

Recent studies have implicated the extracellular signalregulated kinase (Erk, a MAPK family member) cascade in neuronal plasticity and in long-term memory (English and Sweatt 1996; Martin et al. 1997; Kanterewicz et al. 2000; Wu et al. 2001). The Erk cascade is stimulated by extracellular stimuli and the kinase is activated when dually phosphorylated at the TEY motif by the upstream kinase, mitogen-activated protein kinase kinase (MEK) (Payne et al. 1991; Her et al. 1993). PD098059, a cell-permeable inhibitor of MEK, can effectively block the Erk cascade (Alessi et al. 1995) and has been extensively used to examine the role of Erk in vivo. For example, our laboratory has shown that intrahippocampal PD098059 administration blocks longterm memory in the water maze task without any effect on short-term memory (Blum et al. 1999). In addition, it has been reported that PD098059 administration blocks longterm memory in taste aversion, fear conditioning, and passive avoidance tasks (Berman et al. 1998; Schafe et al. 1999; Walz et al. 1999). In this report, we have used PD098059 to investigate the role of Erk activity in the EC in long-term spatial memory. We report that Erk inhibition in the EC impairs performance in the hidden platform version of the

LEARNING \& MEMORY 9:156-166 @ 2002 by Cold Spring Harbor Laboratory Press ISSN1072-0502/02 \$5.00

$$
\begin{array}{llllllllllllllll} 
& E & A & R & N & I & N & G & \mathbf{Q} & M & E & M & O & R & Y \\
\text { www.learnmem.org } & & &
\end{array}
$$


Morris water maze, and that this deficit can be overcome with pretraining.

\section{RESULTS}

The MEK inhibitor PD098059 has been previously shown to be relatively specific for the Erk cascade (Alessi et al. 1995). Our laboratory has independently shown that intrahippocampal infusion of $2.0 \mu \mathrm{g}$ PD098059 does not inhibit the activities of calcium/calmodulin-dependent protein kinase, protein kinase A, stress-activated protein kinase, or protein

\section{PD098059 Infused Into the EC Inhibits Erk Phosphorylation}

kinase C (Blum et al. 1999). When administered intrahippocampally, this dosage and a 10-fold lower concentration (0.2 $\mu \mathrm{g}$ ) of PD098059 were previously found to be effective in decreasing Erk phosphorylation in the hippocampus and caused an impairment in long-term spatial memory (Blum et al. 1999). To examine the effectiveness of PD098059 in blocking Erk phosphorylation in the EC, animals were infused with $0.2 \mu \mathrm{g}$ of PD098059 into one EC and an equal volume of vehicle into the contralateral cortex. The phosphorylation of Erk was examined in the EC and in the dorsal hippocampus using immunohistochemistry as stated in the Materials and Methods section. Figure 1 shows representative photomicrographs of slices taken from entorhinal-infused animals. By $10 \mathrm{~min}$ after the infusion of PD098059, a reduction in Erk phosphorylation in the EC can be seen compared with the vehicle-infused contralateral side (Fig.
A

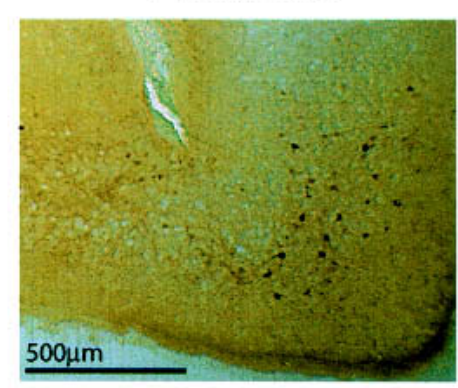

B
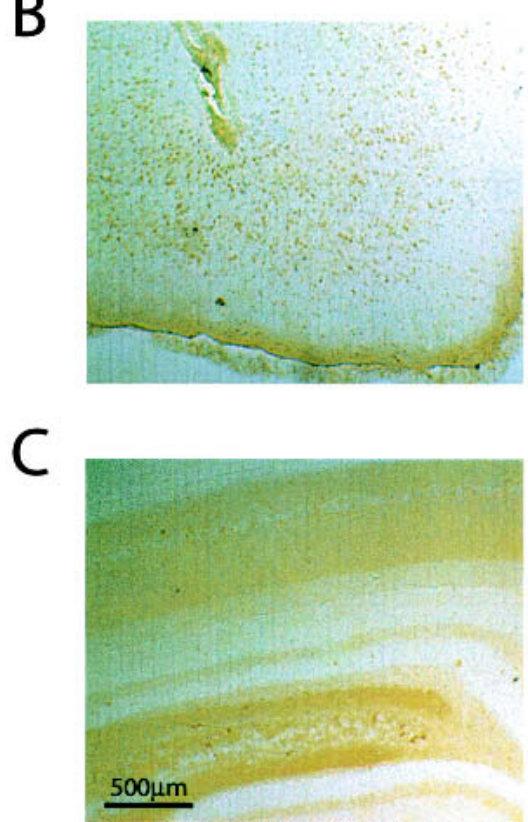

PD098059
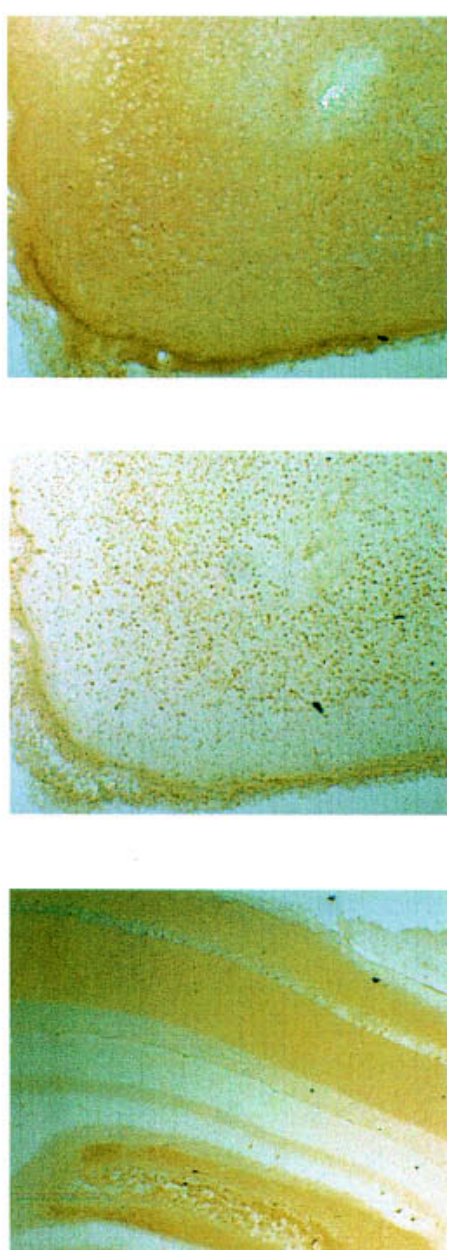

Figure 1 PD098059 infusion into the entorhinal cortex (EC) prevents extracellular signal-regulated kinase (Erk) activation. (A) Representative photomicrographs showing decreased phospho-Erk immunoreactivity in the entorhinal area after $0.2 \mu \mathrm{g}$ PD098059 infusion into one side compared with the vehicle-infused contralateral side (10-min time point). (B) In adjacent slices, $0.2 \mu \mathrm{g}$ PD098059 does not decrease CREB immunoreactivity. (C) In the dorsal hippocampus in the same animal, $0.2 \mu \mathrm{g}$ PD098059 infused into the EC does not decrease phospho-Erk. 1A). Qualitatively similar results were observed at the 20-min time point (data not shown). Figure 1B shows adjacent slices processed with antibodies against CREB (Ca2+/cAMP responsive element binding protein), showing that infusion of $0.2 \mu \mathrm{g}$ PD098059 does not affect the general immunoreactivity of the tissue. To confirm that phospho-Erk immunoreactivity in the dorsal hippocampus is unaffected by intraentorhinal infusions, immunohistochemistry using dorsal hippocampal sections was performed. Figure 1C shows representative photomicrographs of the dorsal hippocampi from the same animal shown in Figure 1A. No difference in phospho-Erk immunoreactivity was observed between the drug- and vehicle-infused sides.

\section{Cannulae Site Verification}

After the completion of all behavioral studies, the sites of infusion were confirmed by histological analysis. Animals with infusion sites that did not fall within the EC and within $0.8 \mathrm{~mm}$ rostral-caudal of the target site were excluded from the analysis. Figure 2 shows the infusion sites of the animals that were included in the one-room and two-room experiments.

\section{Post-Training Infusion of PD098059 Into the EC Blocks Long-Term Spatial Memory}

To investigate whether Erk activity in the EC participates in spatial memory storage, a post-training infusion paradigm was used. Immediately after the completion of train-

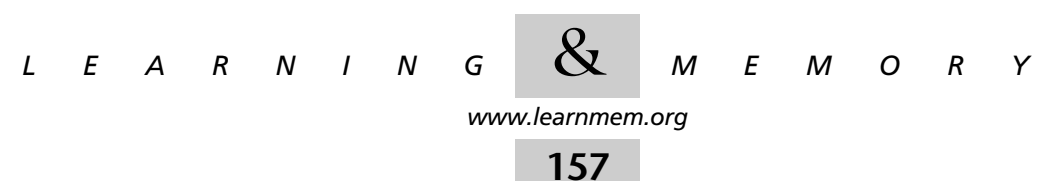




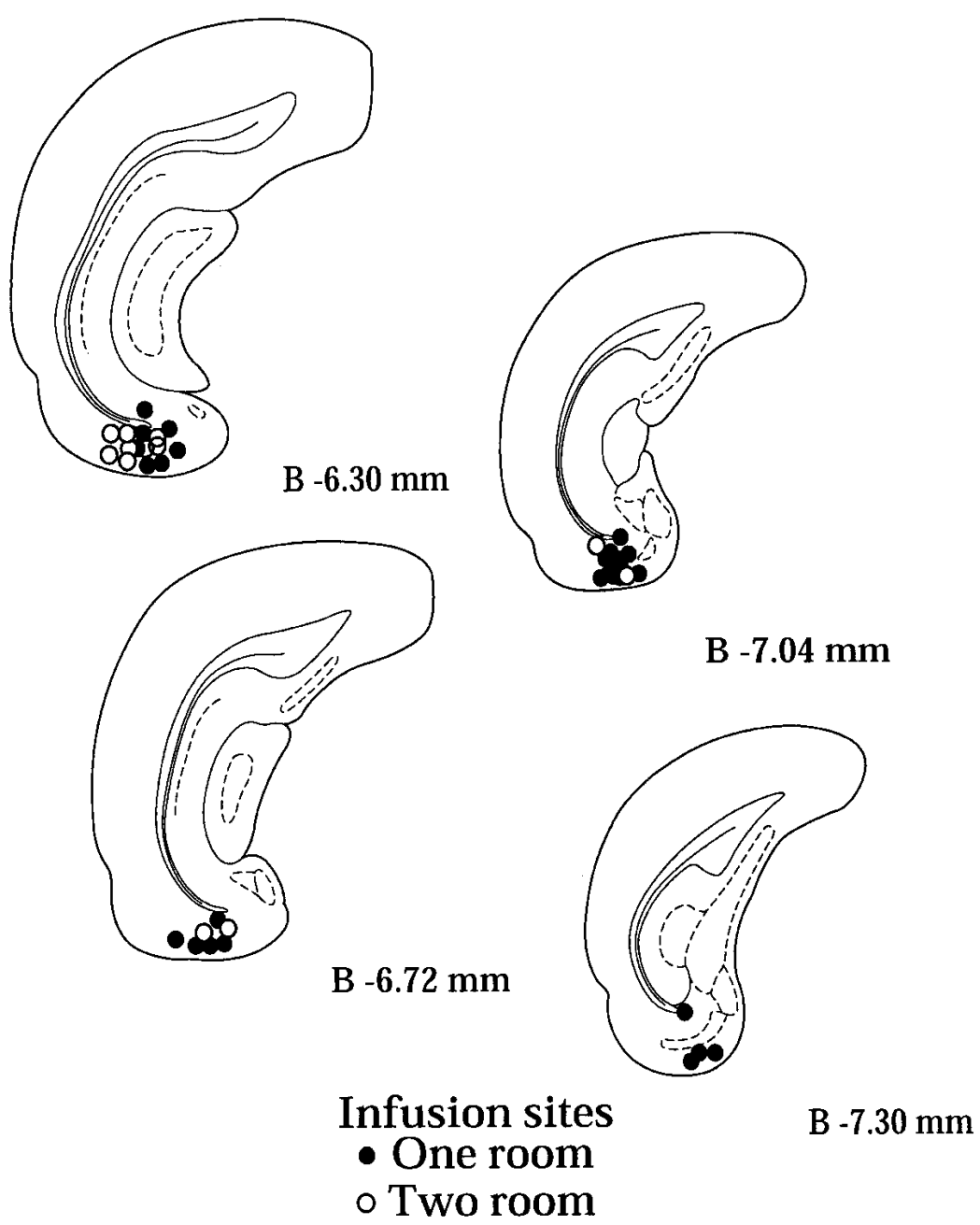

Figure 2 Infusion sites in the EC. Infusion sites in the entorhinal area for all behavioral experiments as shown on coronal atlas plates taken from Paxinos and Watson (1997) Infusion sites are indicated by circles. Only animals that had infusion sites within the EC and that were $0.8 \mathrm{~mm}$ rostral-caudal of the target site were kept for further analysis.

ing, animals were randomly divided into two groups and then bilaterally infused with either vehicle or $0.2 \mu \mathrm{g}$ PD098059. Figure 3A shows that infusion of PD098059 into the EC immediately after training results in significantly longer latencies to cross the previous platform location (gray annulus) during the probe trial administered $48 \mathrm{~h}$ later (PD098059, 39.43 $46.7 \mathrm{sec;}$ vehicle, $16.72 \pm 5.59 \mathrm{sec}$; $p<.05)$. Analysis of the swim speed for each group did not reveal any significant differences (PD098059, 27.8 \pm 1.1 $\mathrm{cm} / \mathrm{sec}$; vehicle, $28.4 \pm 1.9 \mathrm{~cm} / \mathrm{sec}$; n.s.). Representative swim paths for vehicle- and PD098059-infused animals are shown in Figure 3B.

In addition to longer latencies to the platform, further analysis of the probe trial performances revealed several differences between the vehicle- and drug-infused animals. Figure $3 \mathrm{C}$ shows that before the first annulus crossing, drug- infused animals spent more time swimming in the outer $50 \%$ of the tank (dwell time) compared with the vehicle-infused controls (PD098059, $30.28 \pm 6.60$ sec; vehicle, $10.13 \pm 4.35 \mathrm{sec} ; p<.05)$. An analysis of swimming behavior in a smaller ring (one platform diameter in width) right next to the wall shows that drug and vehicle groups are not significantly different in dwell time in this ring before the first crossing (vehicle, 9.67 \pm 4.19; PD098059, 20.9 \pm 6.22 , n.s.). When examined for initial heading direction, animals infused with PD098059 had significantly increased heading error (PD098059, 93.94 $\pm 10.74 \mathrm{deg}$; vehicle, $37.99 \pm 11.93 \mathrm{deg} ; p<.05)$ (Fig 3D).

To test whether the drug-infused animals are reverting to an initial exploratory strategy, a comparison of the first training trials with the probe trial performance of vehicle- and drug-infused animals for dwell time in the outer $50 \%$ and for heading error was performed. Analysis of dwell time in the outer $50 \%$ does not show a significant group by trial interaction (two-way repeated measures analysis of variance [ANOVA], $F=1.91$ ), but does show a significant trial effect $(F=28.176 ; p<.001)$. Post-hoc analysis using a Student-NewmanKeuls test shows that both groups show a significant decrease in dwell time in the outer $50 \%$ in the probe trial compared with the initial trial (vehicle: first trial $46.01 \pm 6.0 ;$ probe $10.13 \pm 4.4, \quad p<.05$; PD098059: first trial $54.16 \pm 3.8$; probe $30.28 \pm 6.6, p<.05)$. However, there is also a significant group effect $(F=4.562$, $p<.05)$, as already mentioned, there is a significant difference between the drug and vehicle animals in the probe trial (see Fig 3C). Analysis of heading error shows a significant group by trial interaction (two-way repeated measures ANOVA; $F=13.484 ; p<.005)$ with the vehicle-infused animals showing a significant decrease in heading error in the probe trial compared with the first trial (first trial $71.01 \pm 8.2$; probe $38.0 \pm 11.9$ ), and the druginfused animals showing a significant increase in heading error (first trial 64.9 \pm 11.9 ; probe $93.9 \pm 10.7$ )

No significant differences were observed between the two groups in the number of total attempts (PD098059, $3.66 \pm 0.73$; vehicle, $4.71 \pm 0.81$; n.s.) or in the number of successful attempts during the probe trial (PD098059, $1.67 \pm 0.53$; vehicle, $2.57 \pm 0.53$; n.s.). The lack of a difference in successful attempts does not appear to be attributable to circling at an appropriate distance from the tank

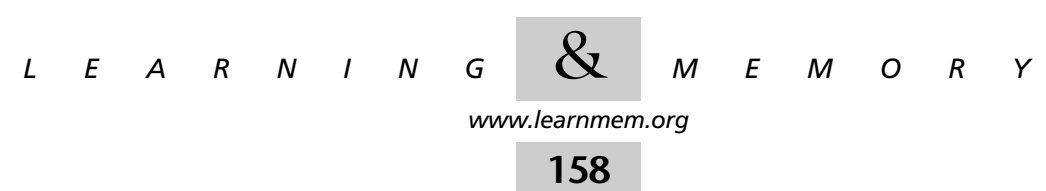


A

B

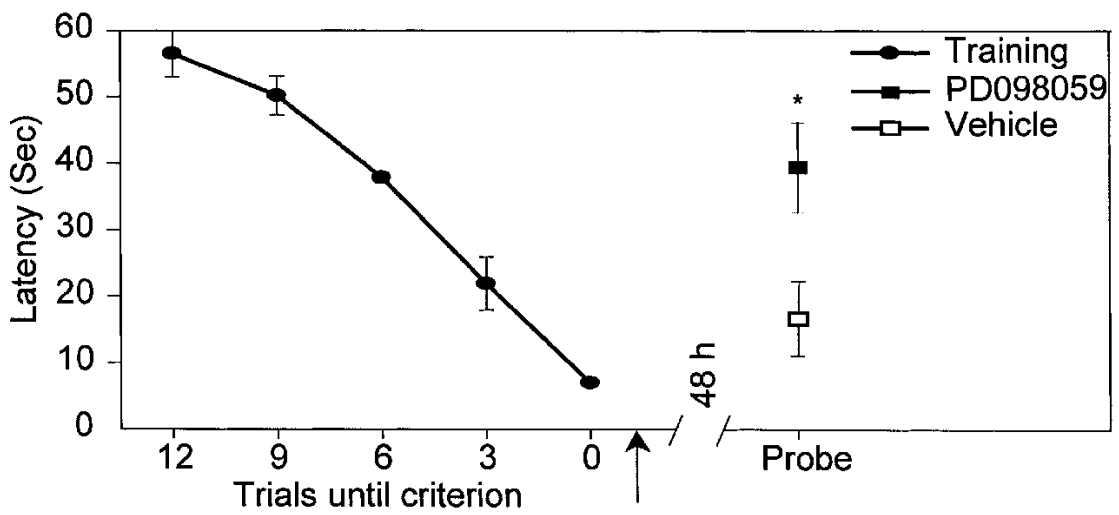

(ave. of three trials)
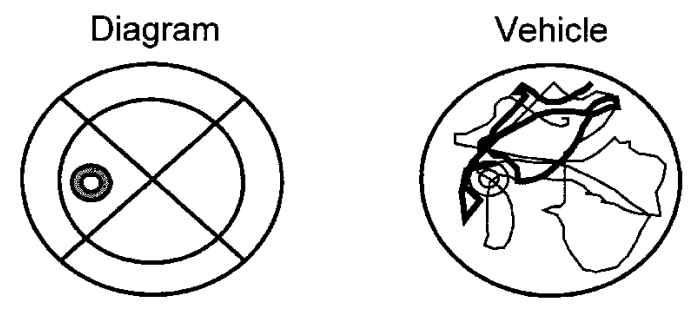

$0.2 \mu \mathrm{g}$ PD098059

C

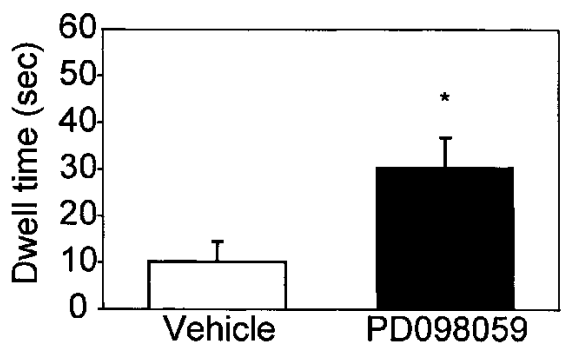

D

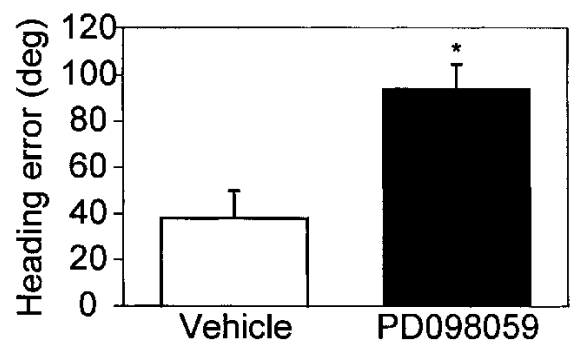

E

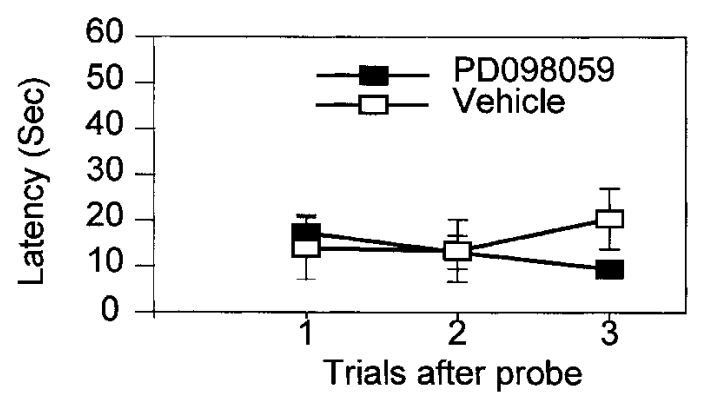

Figure 3 Infusion of PD098059 into the EC after training in the Morris water maze blocks long-term memory. Arrow indicates time of infusion $(0.2 \mu \mathrm{g} / \mathrm{side}$ of PD098059 $[n=9]$ or vehicle $[n=7])$. $(A)$ Latency to the platform location during training and the probe trial. $(B)$ Representative traces of the probe trials for vehicle- and drug-infused animals. $(C$ ) Dwell time in the outer $50 \%$ of the tank before the first successful attempt during the probe trial. (D) Heading error as the angle away from the target (deg) leaving the entry quadrant during the probe trial. $(E)$ Latency to the platform during retraining. Data are presented as the mean \pm standard error of mean $(\mathrm{SEM}), * p<.05$.

wall, as inspection of the probe trials did not reveal any signs of undirected circling behavior. When reexposed to the platform and given three more training trials, drug-in- fused animals showed control levels of performance, indicating that there were no long-term effects of the drug infusion (Fig 3E).

$$
\begin{array}{lllllllllllllll}
\text { L } & E & A & R & N & I & N & G & \mathbf{Q} & M & E & M & O & R & Y \\
\text { www.learnmem.org } & & & & &
\end{array}
$$




\section{Pretraining in a Separate Water Maze Facilitates Training}

Pretraining has been used to help distinguish between the different components of spatial learning (for a review, see Cain 1998). With pretraining, the animals become familiar with the general task requirements and learn to use a mapping strategy (using the relational properties of distal cues) to solve the task. During the training in the second room, the rats then use these acquired skills to solve the novel place problem (Whishaw 1989; Bannerman et al. 1995).

To investigate which component of memory Erk activity in the EC might be storing, a pretraining protocol, similar to the one used by Bannerman et al. (1995), was used with a new group of animals. To confirm that animals learned the task requirements and the strategy for solving the maze during pretraining, the performance of the animals during pretraining and training was compared. If the pretraining allowed the animals to learn the strategy for solving the task, then pretraining should facilitate training. Figure $4 \mathrm{~A}$ shows that the latency to the platform on the first training trial is significantly decreased when compared with the first pretraining trial (Blue room $58.02 \pm 1.37$; Yellow room $41.94 \pm 3.91, p<.005)$. This is consistent with the results reported by Keith and McVety (1988) in which they showed that pretrained (PT) animals had shorter latencies to the platform on the first training trial compared with animals that were just exposed to the procedural aspects of the task. In addition, the number of times that animals failed to remain on the hidden platform after finding it was significantly decreased for training compared with pretraining (Blue room $0.48 \pm 0.19$; Yellow room $0.0 \pm 0.0, p<.05$ ) Because the tank used for training in the Yellow room is $56 \%$ larger than the tank used for pretraining in the Blue room (making the task in the Yellow room more difficult), a direct comparison between training curves or the number of trials to reach criterion would not necessarily be an accurate measure of facilitation (Mactutus and Booze 1994). However, a comparison of the training curves and the num-
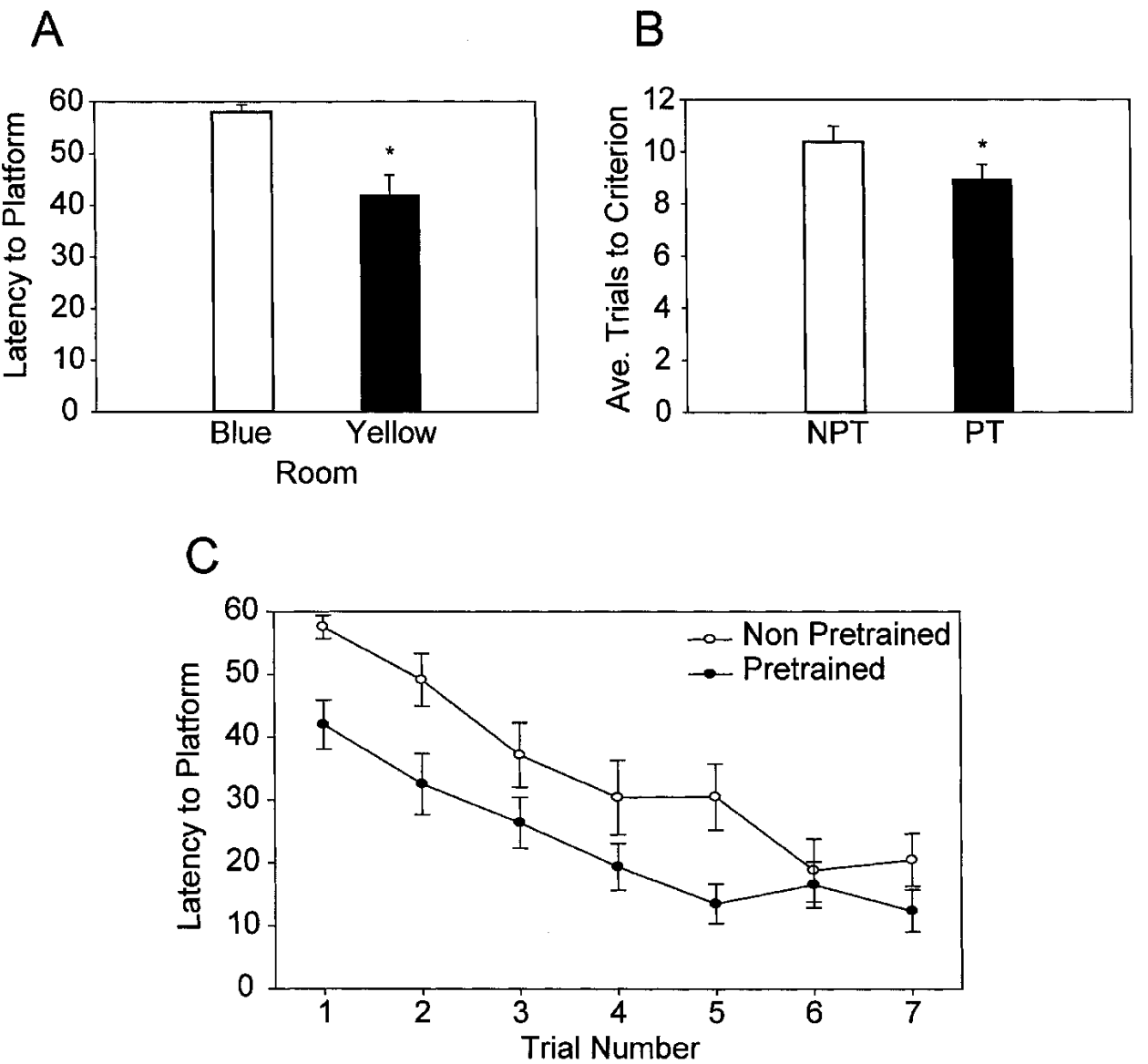

Figure 4 Pretraining in a separate water maze facilitates training. (A) Latency to the platform during the first pretraining trial (Blue) versus the first training trial (Yellow). (B) Average number of trials to criterion for non-pretrained (NPT) animals from Experiment 1 versus the pretrained (PT) animals from Experiment 2. (C) Training curves broken down into individual trials. Latency to platform during the first seven training trials for NPT animals from Experiment 1 versus the PT animals from Experiment 2 (two-way repeated measures analysis of variance [ANOVA] on Ranks NPT versus PT $p<.05)$. Data are presented as the mean \pm SEM, $* p<.05$.

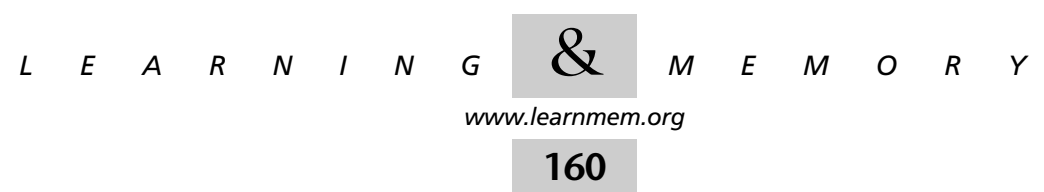


ber of trials to reach criterion between the non-pretrained (NPT) animals from Experiment 1 and the PT animals from Experiment 2, which were both trained in the same tank using the same protocol, also shows a significant facilitation effect of pretraining. Figure $4 \mathrm{~B}$ shows that the number of trials to reach criterion is significantly decreased in the PT group compared with the NPT group (NPT 10.38 \pm 0.61 ; PT $8.96 \pm 0.55 ; p<.05)$. Figure $4 \mathrm{C}$ shows the initial portion of the training curves broken down into individual trials, with the PT group showing significantly shorter latencies to the platform (two-way repeated measures ANOVA on Ranks NPT versus PT, $p<.05)$. However, these experiments were conducted successively, so the statistical analysis should be treated with caution.

\section{Pretraining in a Separate Water Maze Prevents the Memory Deficit Induced by PD098059 Infusion Into the EC}

Figure $5 \mathrm{~A}$ shows that after the pretraining (in the Blue room), all animals show long-term memory for the location of the hidden platform. After the probe trial, animals were trained in a separate water maze in a different room (the Yellow room). Immediately after the completion of training in the Yellow room, animals were randomly divided into two groups and infused with either $0.2 \mu \mathrm{g}$ PD098059 or an equal volume of vehicle. Figure $5 \mathrm{~A}$ shows that animals infused with PD098059 into the EC after training in the Yellow room were not significantly different than vehicle-infused animals in latency to cross the platform location (gray annulus) when tested in a probe trial $48 \mathrm{~h}$ later (PD098059, $27.8 \pm 6.0 \mathrm{sec}$; vehicle, $24.8 \pm 5.4 \mathrm{sec}$; n.s.). Analysis of the swim speed for each group also did not reveal any significant differences (PD098059, $29.9 \pm 1.2 \mathrm{~cm} / \mathrm{sec}$; vehicle, $28.1 \pm 1.1 \mathrm{~cm} / \mathrm{sec}$; n.s.). Representative swim paths for vehicle- and PD098059-infused animals are shown in Figure $5 \mathrm{~B}$. Consistent with the latencies, Figure 5C shows that the drug- and vehicle-infused groups had no significant differences in the amount of time swimming in the outer $50 \%$ of the tank before the first annulus crossing (PD098059, $19.8 \pm 6.0$; vehicle, $15.2 \pm 4.3$; n.s.). In addition, no significant difference was detected in heading error between the two groups (PD098059, 68.1 \pm 10.9 ; vehicle, $63.8 \pm 10.2$; n.s.) (Fig. 5D). Drug-infused animals were not significantly different in either the total number of attempts (PD098059, $5.8 \pm 0.9$; vehicle, $4.7 \pm 0.6$; n.s.) or the number of successful attempts (PD098059, $2.1 \pm 0.4$; vehicle, $2.0 \pm 0.4$; n.s.) when compared with the vehicle-infused animals. Figure $5 \mathrm{E}$ shows that drug-infused animals show control levels of performance on the retraining trials.

\section{DISCUSSION}

Two novel findings are presented in this report that are relevant to the involvement of the EC in learning and memory and the molecular mechanisms underlying this in- volvement. First, Erk activity in the EC is necessary for the long-term memory of a spatial task, the Morris water maze. Second, pretraining in a distinctly different water maze alleviates the deficit seen after Erk blockade in this task. These findings show a crucial role for the Erk cascade in the EC in storing a component of long-term spatial memory.

The involvement of the EC in long-term spatial memory has been the subject of numerous lesion studies, although the conclusions have been varied because of differences in the extent and type of lesion. For example, several studies have reported deficits in the acquisition of water or radial arm maze tasks after lesions of the EC (Olton et al. 1978; Holscher and Schmidt 1994; Johnson and Kesner 1994; Cho and Jaffard 1995; Nagahara et al. 1995; Galani et al. 1997, 1998; Hardman et al. 1997; Ferbinteanu et al. 1999; Eijkenboom et al. 2000; Oswald and Good 2000). In contrast, other studies that have performed fiber-sparing lesions of the EC do not report any deficits in the acquisition or retention of these tasks (Bouffard and Jarrard 1988; Pouzet et al. 1999; Bannerman et al. 2001). Incomplete lesions sparing parts of the EC (Bouffard and Jarrard 1988) or extensive training in other tasks before maze training (Pouzet et al. 1999; Bannerman et al. 2001), however, have complicated the interpretation of these studies. Furthermore, the absence of a deficit in these pretraining lesion studies may be attributable to compensation by alternative problem-solving strategies. Studies using post-training lesions of the EC (both fiber-sparing and nonfiber sparing) have observed deficits in retention, indicating that the $\mathrm{EC}$ itself may be a site for memory storage (Schenk and Morris 1985; Cho et al. 1993, 1995).

We have previously shown that behavioral training in a spatial memory task results in Erk activation in the dorsal hippocampus and that blockade of this activation impairs long-term spatial memory, indicating a role for Erk in the plasticity-related changes associated with long-term memory. To investigate whether similar mechanisms take place in the EC, post-training intraentorhinal administration of an inhibitor of Erk activation, PD098059, was performed. This infusion protocol was used to specifically address the question of the role of the EC in the retention of this task, as opposed to its role in the acquisition of this task. During a probe trial $48 \mathrm{~h}$ after the completion of training, spatial memory was found to be significantly impaired in the druginfused group compared with the vehicle-infused group (Fig. 3). This deficit appeared to be attributable to the blockade of Erk activity in the EC, as immunohistochemical analysis did not reveal any influence of the infusion on phosphoErk immunoreactivities in the dorsal hippocampus (Fig. 1). Analysis of the probe trial performance revealed several differences between animals infused with PD098059 and control animals, including longer latencies to the platform location (gray annulus), increased initial swimming in the

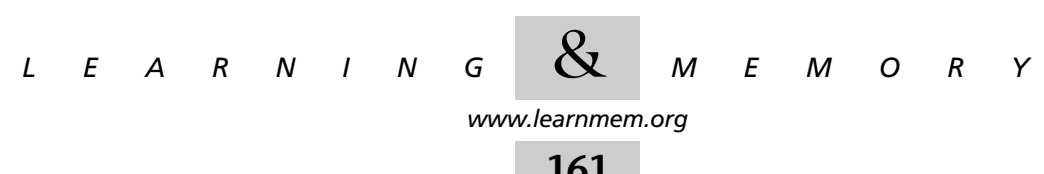


A

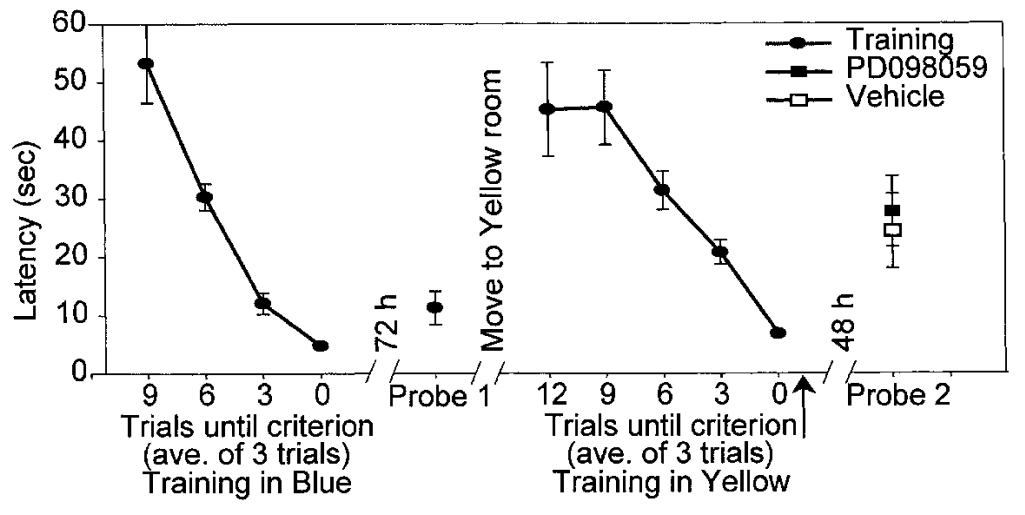

B
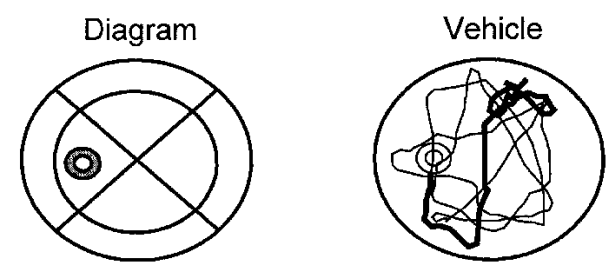

$0.2 \mu \mathrm{g}$ PD098059

C

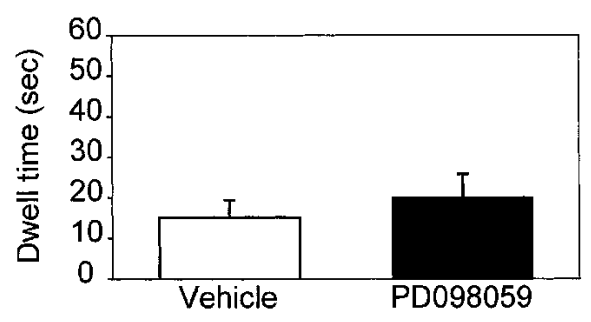

D

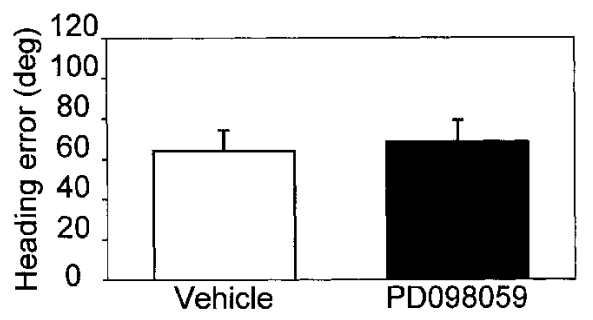

$E$

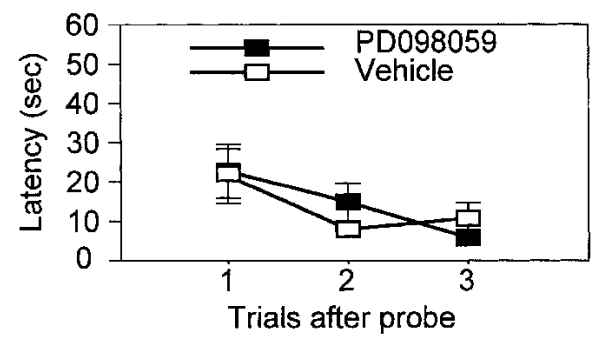

Figure 5 Pretraining prevents the memory deficit induced by PD098059 infusion into the EC. Arrow indicates time of infusion $(0.2 \mu \mathrm{g} / \mathrm{side}$ of PD098059 $[n=10]$ or vehicle $[n=13])$. (A) Latency to platform location during pretraining, the first probe trial, training, and the second probe trial. (B) Representative traces of the probe trials for animals from the vehicle $(n=13)$ and drug $(n=10)$ groups. (C) Dwell time in the outer $50 \%$ of the tank before the first successful attempt during the probe trial. (D) Heading error as the angle away from the target (deg) leaving the entry quadrant during the probe trial. (E) Latency to the platform location during retraining. Data are presented as the mean \pm SEM.

outer $50 \%$ of the tank (which was not due to the animals simply searching the tank wall for a means of escape), and larger initial heading errors. The latency to platform and heading error measures are quite sensitive to the degree of learning (Morris 1984). An increase in the latency to platform is a commonly used index of a memory deficit, as other studies using a 1-d training protocol have used latency to platform as a learning or retention measure and have reported increased latencies as an indication of memory impairment (Guzowski and McGaugh 1997; Blum et al. 1999; Teather et al. 2002). It is interesting that there was no difference in the number of total or successful attempts made by the two groups (Fig. 3E). This is consistent with a previous study by Schenk and Morris (1985) in which animals with post-training lesions of the EC did not show a preference for the training quadrant in a transfer test (probe

$$
\begin{array}{lllllllllllllll}
L & E & A & R & N & I & N & G & \mathcal{Q} & M & E & M & O & R & Y \\
\text { www.learnmem.org } & &
\end{array}
$$


trial), but their frequency in crossing the platform location was no different than control animals.

The impairments we observed with PD098059 infusions after training appeared to be more related to memory deficits for search strategies than for the location of the platform. The drug-infused animals seem to have reverted back to an exploratory search pattern that is less accurate than a more developed directed search pattern. This type of strategy might include wall-directed, or start-directed swims, and large heading errors, similar to the strategy used at the beginning of training. A difference in performance between the initial trials and the probe trials for the vehicleinfused animals, but not the drug-infused animals, would indicate that rats infused with PD098059 revert to their initial exploratory strategy. For heading error, the vehicleinfused animals show a decrease, and the drug-infused animals show an increase, in the probe trial compared with the first training trial. That the drug-infused animals showed an increase in heading error instead of simply no change may be because the animals were exposed to the platform immediately before the first training trial and not before the probe trial. For dwell time in the outer $50 \%$, both groups show a significant decrease in the probe trial compared with the initial trial, with the vehicle-infused animals significantly decreased compared with the drug-infused animals. The decrease in dwell time in the outer 50\% during the probe trial compared with the first training trial seen in the drug-infused group, combined with control levels of swimming against the wall, indicates that the deficit is not attributable to the rats searching the tank wall for a means of escape. These results together support our conclusion that the drug-infused animals are reverting to a less-developed, wall-directed search strategy. Although the drug-infused animals' search fits an exploratory pattern, both groups still crossed the platform location (gray annulus) with similar frequency, indicating intact memory for the location of the platform. It has been suggested that an animal spontaneously reverts to an exploratory search strategy when it finds itself in a novel situation or when a familiar situation has changed in some way (Whishaw and Mittleman 1986), so it is unclear from the probe trial analysis whether the animals lack a search strategy or whether their "cognitive map" of the room has been lost such that the room appears "novel."

To address this possibility, animals were pretrained, allowing them to consolidate information regarding the requirements of the task and an optimal strategy for solving it. Thus, only the platform location in relation to the distal cues would be learned in the subsequent training, which is supported by the data showing facilitated training as a result of pretraining (see Fig. 4). After this training in the second room, animals were infused with PD098059 or vehicle. When tested with a probe trial $48 \mathrm{~h}$ later, there were no significant differences between the two groups for any of the performance factors examined. Although the mean val- ues for vehicle-infused animals for the performance criteria examined were elevated for the probe trial in Experiment 2 compared with Experiment 1, these differences were not statistically significant. These results support the idea that Erk activity in the EC is not involved in storing the specific location of the platform or the "map" of the room, but that it may be important for storing the optimal search strategy or rule for solving the maze. This idea is consistent with a theory proposed by Whishaw and Mittleman (1986) suggesting that the EC is involved in the retention of search strategies. The present study cannot rule out the possibility that the lack of a deficit in the drug-infused animals was attributable to a lack of novelty for the task because of pretraining or to the animal's ability to compensate for a deficit attributable to greater experience with the task.

If the EC is involved in strategy selection and retention, the process of deciding which stimuli are irrelevant may be a part of the process of strategy selection. In the study by Schenk and Morris (1985), animals were trained to ignore a decoy (floating platform) to successfully navigate to a stable platform in the water maze. Animals with EC lesions did not learn to avoid the floating platform, and the investigators concluded that the lesioned animals could not discriminate between the two platforms. However, both lesion groups were consistently above chance in choosing the rigid platform, indicating that they could not learn that the floating platform was irrelevant to solving the task.

The results presented here are also consistent with latent inhibition studies. EC lesions also block latent inhibition, which is the phenomenon by which preexposure to the context and the shock prevents later fear conditioning and is thought to be a measure of the ability to ignore irrelevant stimuli.

Since Erk activation was first observed after hippocampal long-term potentiation (English and Sweatt 1996), several studies have shown that Erk activity is a critical component of long-term memory formation. For example, translocation of Erk into the nucleus of Aplysia presynaptic neurons has been observed during serotonin-induced longterm facilitation, a correlate of long-term memory. Blockade of Erk activity in these neurons impairs long-term facilitation without any affect on short-term facilitation (Martin et al. 1997). Similarly, training in a hippocampus-dependent task is associated with activation and translocation of Erk in CA1/CA2 dorsal hippocampal neurons, and inhibition of Erk impairs long-term, but not short-term, spatial memory (Blum et al. 1999). Erk activity has also been reported after training in classical conditioning paradigms (Crow et al. 1998), associative learning (Atkins et al. 1998), inhibitory avoidance (Cammarota et al. 2000; Alonso et al. 2002), and taste discrimination (Berman et al. 1998). Its activation in areas involved in specific types of memory has been shown to be necessary for that type of learning. For example, the insular cortex and taste aversion (Berman et al. 1998), the

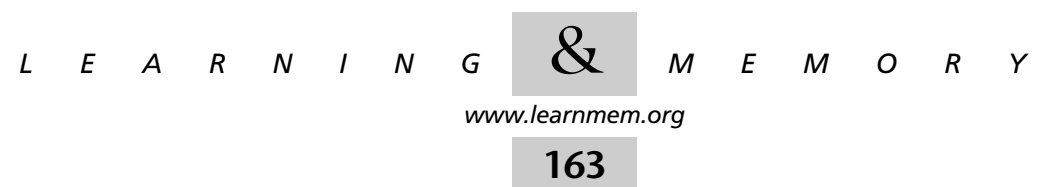


amygdala and fear conditioning (Schafe et al. 2000), the hippocampus and spatial learning (Blum et al. 1999), and the hippocampus, EC, amygdala, and parietal cortex in stepdown inhibitory avoidance (Walz et al. 1999, 2000; Izquierdo et al. 2000b). The Erk cascade has also been shown to be necessary for retrieval in inhibitory avoidance tasks in the EC (Barros et al. 2000), hippocampus (Barros et al. 2000; Izquierdo et al. 2000a; Szapiro et al. 2000), parietal cortex, and amygdala (Barros et al. 2000). The repeated demonstration of the involvement of this kinase in longterm memory storage with different tasks indicates a key role for this enzyme in neuronal plasticity.

The effectiveness of PD098059 to inhibit long-term spatial memory when administered immediately after training into either the dorsal hippocampus or the EC indicates that similar molecular cascades are activated in these two structures, perhaps in parallel, as a result of learning. This is in agreement with the classification of Bontempi et al. (1999) of the EC as a hippocampal formation structure that shows a similar temporal pattern of involvement in longterm memory. Further study into the details of the deficits after Erk inhibition in these two structures may elucidate similarities and/or differences in their contributions to longterm memory storage.

\section{METHODS}

\section{Subjects}

Adult male Long-Evans rats (220-250 g) were obtained from Charles River Laboratories. Rats were housed individually on a 12-h light/dark cycle with ad libitum access to food and water.

\section{Surgery}

All protocols involving the use of animals were in compliance with the National Institutes of Health's Guide for the Care and Use of Laboratory Animals and were approved by the Institutional Animal Care and Use Committee. Rats were initially anesthetized with $4 \%$ isoflurane with a $2: 1 \mathrm{~N}_{2} \mathrm{O}: \mathrm{O}_{2}$ mixture and were maintained via a facemask under a $2 \%$ isoflurane/2: $1 \mathrm{~N}_{2} \mathrm{O}: \mathrm{O}_{2}$ mixture. A small burr hole in the skull was prepared to allow the implantation of chronic guide cannulae. The guide cannulae were aimed $1.5 \mathrm{~mm}$ above the entorhinal area and bilaterally implanted using the following coordinates: AP $-6.7, \mathrm{~L} \pm 5.5$, and V 6.0 (Paxinos and Watson 1997). Guides were secured to the skull with screws and dental cement. Animals were allowed to recover from the surgery for 10 $\mathrm{d}$ before the initiation of behavioral testing.

\section{Drug Preparation and Infusion}

PD098059 (Biomol) was initially dissolved in DMSO and then diluted in sterile saline before use. Freely moving animals were bilaterally infused with $1 \mu \mathrm{L} /$ side of $0.2 \mu \mathrm{g}$ PD098059 (in 4\% DMSO) or vehicle (4\% DMSO in saline) using a dual syringe infusion pump (Stoelting) at a rate of $0.25 \mu \mathrm{L} / \mathrm{min}$. The infusion cannulae extended $1.5 \mathrm{~mm}$ beyond the guide cannulae to give a final depth of $7.5 \mathrm{~mm}$.

\section{Behavioral Training}

All behavioral training was performed by an experimenter blind to the treatment groups. Spatial memory was examined using a pro- tocol similar to the hidden platform version of the Morris water maze task, as was described previously (Blum et al. 1999).

\section{Experiment 1}

Animals were trained in a room off a yellow corridor, which will be called the "Yellow room," using a water-filled metal tank $1.4 \mathrm{~m}$ in diameter surrounded by several extra-maze cues that were kept constant throughout the training and testing procedures. A round platform $11 \mathrm{~cm}$ in diameter was submerged $2.5 \mathrm{~cm}$ below the water level, and white opaque nontoxic paint was added to the water to hinder visibility. Animals were initially placed on the platform for $30 \mathrm{sec}$ to allow them to become familiar with the tank and extramaze cues. For each training trial, the rats were placed in the pool facing the wall in one of four random locations and given $60 \mathrm{sec}$ to find the platform. Animals were allowed to rest on the platform for $30 \mathrm{sec}$ before being returned to warm training cages. Animals that failed to find the platform were led there by the experimenter. An intertrial interval of $4 \mathrm{~min}$ separated the trials. Animals were trained until they found the hidden platform three consecutive times with an average latency of $\leq 10 \mathrm{sec}$. On average, animals required 10-16 training trials to reach this criterion. Animals that failed to reach this criterion after 16 trials were eliminated from the study. In Experiment 1, five animals did not satisfy the criterion, whereas in Experiment 2, two animals did not satisfy the criterion. Immediately after training, animals were bilaterally infused with either 0.2 $\mu \mathrm{g}$ PD098059 or vehicle $(1 \mu \mathrm{L} /$ side at $0.25 \mu \mathrm{L} / \mathrm{min})$ and were returned to their home cages until retention testing. Spatial memory was assessed $48 \mathrm{~h}$ later with a 60 -sec probe trial in which the platform was removed. Movement within the maze was recorded using a digital camera and Chromotrack tracking software (San Diego Instruments). After completion of the probe trial, the platform was replaced and the animals were exposed to the platform for $30 \mathrm{sec}$ and then immediately given three retraining trials to assess any nonspecific or lingering effects of the drug infusion.

\section{Experiment 2}

The procedure used was similar to that outlined by Bannerman et al. (1995). Rats were trained in a room off the blue corridor, which will be called the "Blue room," using a fiberglass tank $1.2 \mathrm{~m}$ in diameter with an 11-cm diameter platform. Platform placement and extra-maze cues were arranged to be distinctly different from those used in the Yellow room. Animals were trained as in Experiment 1 with a criterion of three consecutive trials averaging $<7 \mathrm{sec}$ to adjust for the decreased tank diameter. Spatial memory was assessed $72 \mathrm{~h}$ later with a probe trial as described previously. After the probe trial, animals were trained in the Yellow room, using the same criterion as in Experiment 1. Immediately after training, animals were bilaterally infused with $0.2 \mu \mathrm{g}$ PD098059 or vehicle. Animals were given a probe trial $48 \mathrm{~h}$ later in the Yellow room and retrained as described above.

\section{Probe Trial Analysis}

The tracking software automatically calculates dwell time and entries into labeled zones as well as heading error, which is measured as the angle between the center of the platform and the heading of the animal when leaving the entry quadrant. Computer traces of the animal's movements during the probe trial were printed with the following areas labeled: concentric circles representing the platform location and an area with a diameter $(22 \mathrm{~cm})$ that is twice that of the platform (gray annulus), the perimeter (the outer $50 \%$ of the tank), and the quadrants. The printouts were used to determine the number of platform approaches (attempts) and the number of times these attempts were successful (gray annulus crossings). An

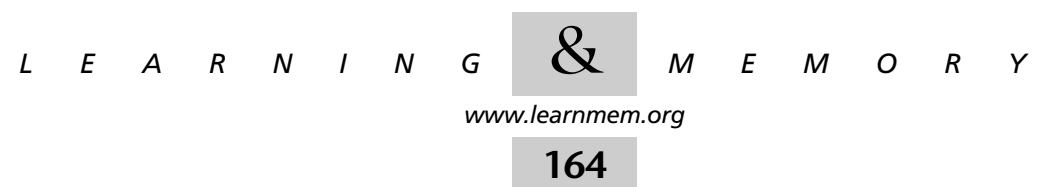


attempt was defined as (1) any time the path of the animal entered or touched the gray annulus; (2) any time the path of the animal showed a sharp turn away from the tank wall $\left(>30^{\circ}\right)$ followed by a straight swim of at least $9 \mathrm{~cm}$ that, if continued, would have resulted in the path of the animal entering the gray annulus; and (3) a longer straight swim for at least $18 \mathrm{~cm}$ in which the rat crossed into the training quadrant and came within $20 \mathrm{~cm}$ of the edge of the platform.

\section{Drug Effectiveness}

A separate group of animals were cannulated as in the infusion experiments and were infused with $0.2 \mu \mathrm{g}$ PD098059 on one side and vehicle contralaterally. The animals were killed 10 to $20 \mathrm{~min}$ later; the brains were removed and cut into $4-\mathrm{mm}$ thick slabs. The slabs were postfixed in ice-cold $4 \%$ paraformaldehyde $15 \%$ picric acid for $48 \mathrm{~h}$, cryoprotected with $30 \%$ sucrose, and sliced into $40-\mu \mathrm{m}$ slices using a cryostat. Free-floating slices were blocked in Tris-buffered saline with $0.1 \%$ Triton X-100 (TTBS) containing 3\% BSA for $30 \mathrm{~min}$. Slices were then incubated for $24 \mathrm{~h}$ at room temperature in anti-phospho Erk1/2 or anti-CREB (rabbit polyclonal antibody, $1: 1000$ Cell Signaling Technologies) in TTBS-3\% BSA. Tissue sections were washed in TTBS after which the tissue was incubated in biotinylated goat anti-rabbit secondary and visualized using $\mathrm{ABC}$ and $\mathrm{DAB}$ kits (Vector Laboratories) following the manufacturer's instructions. The immunoreactivity of phospho-Erk and of CREB was visually compared between the drug- and vehicleinfused sides. However, the present experiments cannot completely rule out an effect on subicular structures because of guide cannulae placement.

\section{Verification of Cannulae Placement}

After the completion of behavioral testing, animals were killed and bilaterally infused with $1.5 \mu \mathrm{L}$ Coomassie blue dye to mark the infusion sites. The brains were then removed, cut into 4 -mm thick slabs, and postfixed in $4 \%$ paraformaldehyde $/ 15 \%$ picric acid for 24-48 hr. Tissue was then cryoprotected in 30\% sucrose, and 40$\mu \mathrm{m}$ cryosections were prepared. Sections including the infusion site were mounted on slides and stained with cresyl violet. Cannulae placement was confirmed, and only animals in which the infusion site was within the EC and within $0.8 \mathrm{~mm}$ rostral-caudal of the target site were kept for further analysis (Experiment 1 vehicle $n=7$, PD098059 $n=9$; Experiment 2 vehicle $n=13$, PD098059 $n=10$ ).

\section{Statistical Analysis}

Statistical significance was determined using a two-tailed Student's $t$ test for unpaired variables when comparing two groups and by using a two-way repeated measures ANOVA test for differences between the training curves. Data were considered significant at $p \leq .05$.

\section{ACKNOWLEDGMENTS}

The authors thank Dr Anthony Wright, Dr. James Knierim, Dr. Jocelyne Bachevalier, Dr. Eric Hargreaves, and Anthony Moore for their invaluable comments and Melanie Moody and Sara Mach for technical support. The work was supported by grants (MH49662, NS35457, T32-NS41226) from the National Institutes of Health.

The publication costs of this article were defrayed in part by payment of page charges. This article must therefore be hereby marked "advertisement" in accordance with 18 USC section 1734 solely to indicate this fact.

\section{REFERENCES}

Alessi, D.R., Cuenda, A., Cohen, P., Dudley, D.T., and Saltiel, A.R. 1995. PD 098059 is a specific inhibitor of the activation of mitogen-activated protein kinase kinase in vitro and in vivo. J. Biol. Chem. 270: 27489-27494.

Alonso, M., Viola, H., Izquierdo, I., and Medina, J.H. 2002. Aversive experiences are associated with a rapid and transient activation of ERKs in the rat hippocampus. Neurobiol. Learn. Mem. 77: 119-124.

Atkins, C.M., Selcher, J.C., Petraitis, J.J., Trzaskos, J.M., and Sweatt, J.D. 1998. The MAPK cascade is required for mammalian associative learning. Nat. Neurosci. 1: 602-609.

Bannerman, D.M., Good, M.A., Butcher, S.P., Ramsay, M., and Morris, R.G. 1995. Distinct components of spatial learning revealed by prior training and NMDA receptor blockade. Nature 378: 182-186.

Bannerman, D.M., Yee, B.K., Lemaire, M., Wilbrecht, L., Jarrard, L., Iversen, S.D., Rawlins, J.N., and Good, M.A. 2001. The role of the entorhinal cortex in two forms of spatial learning and memory. Exp. Brain Res. 141: 281-303.

Barros, D.M., Izquierdo, L.A., Mello e Souza, T., Ardenghi, P.G., Pereira, P., Medina, J.H., and Izquierdo, I. 2000. Molecular signalling pathways in the cerebral cortex are required for retrieval of one-trial avoidance learning in rats. Behav. Brain Res. 114: 183-192.

Berman, D.E., Hazvi, S., Rosenblum, K., Seger, R., and Dudai, Y. 1998. Specific and differential activation of mitogen-activated protein kinase cascades by unfamiliar taste in the insular cortex of the behaving rat. J. Neurosci. 18: 10037-10044.

Blum, S., Moore, A.N., Adams, F., and Dash, P.K. 1999. A mitogen-activated protein kinase cascade in the CA1/CA2 subfield of the dorsal hippocampus is essential for long-term spatial memory. $J$. Neurosci. 19: 3535-3544.

Bontempi, B., Laurent-Demir, C., Destrade, C., and Jaffard, R. 1999. Time-dependent reorganization of brain circuitry underlying long-term memory storage. Nature 400: 671-675.

Bouffard, J.P. and Jarrard, L.E. 1988. Acquisition of a complex place task in rats with selective ibotenate lesions of hippocampal formation: Combined lesions of subiculum and entorhinal cortex versus hippocampus. Behav. Neurosci. 102: 828-834.

Cain, D.P. 1998. Testing the NMDA, long-term potentiation, and cholinergic hypotheses of spatial learning. Neurosci. Biobehav. Rev. 22: 181-193.

Cammarota, M., Bevilaqua, L.R., Ardenghi, P., Paratcha, G., Levi, D.S., Izquierdo, I., and Medina, J.H. 2000. Learning-associated activation of nuclear MAPK, CREB and Elk-1, along with Fos production, in the rat hippocampus after a one-trial avoidance learning: Abolition by NMDA receptor blockade. Brain Res. Mol. Brain Res. 76: 36-46.

Cho, Y.H. and Jaffard, R. 1995. Spatial location learning in mice with ibotenate lesions of entorhinal cortex or subiculum. Neurobiol. Learn. Mem. 64: 285-290.

Cho, Y.H., Beracochea, D., and Jaffard, R. 1993. Extended temporal gradient for the retrograde and anterograde amnesia produced by ibotenate entorhinal cortex lesions in mice. J. Neurosci. 13: 1759-1766.

Cho, Y.H., Kesner, R.P., and Brodale, S. 1995. Retrograde and anterograde amnesia for spatial discrimination in rats: Role of hippocampus, entorhinal cortex, and parietal cortex. Psychobiology 23: 185-194.

Crow, T., Xue-Bian, J.J., Siddiqi, V., Kang, Y., and Neary, J.T. 1998. Phosphorylation of mitogen-activated protein kinase by one-trial and multi-trial classical conditioning. J. Neurosci. 18: 3480-3487.

Eijkenboom, M., Blokland, A., and van der Staay, F.J. 2000. Modelling cognitive dysfunctions with bilateral injections of ibotenic acid into the rat entorhinal cortex. Neuroscience 101: 27-39.

English, J.D. and Sweatt, J.D. 1996. Activation of p42 mitogen-activated protein kinase in hippocampal long term potentiation. J. Biol. Chem. 271: 24329-24332.

Fell, J., Klaver, P., Lehnertz, K., Grunwald, T., Schaller, C., Elger, C.E., and Fernandez, G. 2001. Human memory formation is accompanied by rhinal-hippocampal coupling and decoupling. Nat. Neurosci. 4: $1259-1264$.

Ferbinteanu, J., Holsinger, R.M., and McDonald, R.J. 1999. Lesions of the medial or lateral perforant path have different effects on hippocampal

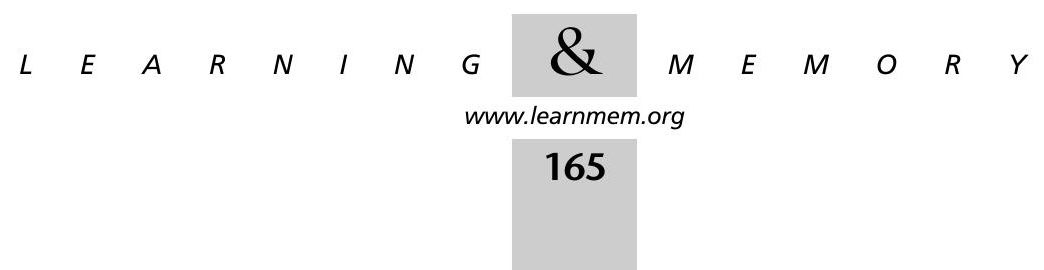


contributions to place learning and on fear conditioning to context Behav. Brain Res. 101: 65-84.

Galani, R., Jarrard, L.E., Will, B.E., and Kelche, C. 1997. Effects of postoperative housing conditions on functional recovery in rats with lesions of the hippocampus, subiculum, or entorhinal cortex. Neurobiol. Learn. Mem. 67: 43-56.

Galani, R., Weiss, I., Cassel, J.C., and Kelche, C. 1998. Spatial memory, habituation, and reactions to spatial and nonspatial changes in rats with selective lesions of the hippocampus, the entorhinal cortex or the subiculum. Behav. Brain Res. 96: 1-12.

Guzowski, J.F. and McGaugh, J.L. 1997. Antisense oligodeoxynucleotide-mediated disruption of hippocampal cAMP response element binding protein levels impairs consolidation of memory for water maze training. Proc. Natl. Acad. Sci. 94: 2693-2698.

Hagan, J.J., Verheijck, E.E., Spigt, M.H., and Ruigt, G.S. 1992. Behavioural and electrophysiological studies of entorhinal cortex lesions in the rat Physiol. Behav. 51: 255-266.

Hardman, R., Evans, D.J., Fellows, L., Hayes, B., Rupniak, H.T., Barnes, J.C., and Higgins, G.A. 1997. Evidence for recovery of spatial learning following entorhinal cortex lesions in mice. Brain Res. 758: 187-200.

Her, J.H., Lakhani, S., Zu, K., Vila, J., Dent, P., Sturgill, T.W., and Weber, M.J. 1993. Dual phosphorylation and autophosphorylation in mitogen-activated protein (MAP) kinase activation. Biochem. J. 296 part. 1): 25-31.

Holscher, C. and Schmidt, W.J. 1994. Quinolinic acid lesion of the rat entorhinal cortex pars medialis produces selective amnesia in allocentric working memory (WM), but not in egocentric WM. Behav Brain Res. 63: 187-194.

Izquierdo, L.A., Barros, D.M., Ardenghi, P.G., Pereira, P., Rodrigues, C., Choi, H., Medina, J.H., and Izquierdo, I. 2000a. Different hippocampal molecular requirements for short- and long-term retrieval of one-trial avoidance learning. Behav. Brain Res. 111: 93-98.

Izquierdo, L.A., Vianna, M., Barros, D.M., Mello e Souza, T., Ardenghi, P., Sant' Anna, M.K., Rodrigues, C., Medinam, J.H., and Izquierdo, I. $2000 \mathrm{~b}$. Short- and long-term memory are differentially affected by metabolic inhibitors given into hippocampus and entorhinal cortex. Neurobiol. Learn. Mem. 73: 141-149.

Johnson, D.L. and Kesner, R.P. 1994. The effects of lesions of the entorhinal cortex and the horizontal nucleus of the diagonal band of broca upon performance of a spatial location recognition task. Behav. Brain Res. 61: 1-8.

Kanterewicz, B.I., Urban, N.N., McMahon, D.B., Norman, E.D., Giffen, L.J., Favata, M.F., Scherle, P.A., Trzskos, J.M., Barrionuevo, G., and Klann, E. 2000. The extracellular signal-regulated kinase cascade is required for NMDA receptor-independent LTP in area CA1 but not area CA3 of the hippocampus. J. Neurosci. 20: 3057-3066.

Keith, J.R. and McVety, K.M. 1988. Latent place learning in a novel environment and the influences of prior training in rats. Psychobiology 16: 146-151.

Kim, J.J. and Fanselow, M.S. 1992. Modality-specific retrograde amnesia of fear. Science 256: 675-677.

Mactutus, C.F. and Booze, R.M. 1994. Accuracy of spatial navigation: The role of platform and tank size. Soc. Neurosci. Abstract 20: 1014

Martin, K.C., Michael, D., Rose, J.C., Barad, M., Casadio, A., Zhu, H., and Kandel, E.R. 1997. MAP kinase translocates into the nucleus of the presynaptic cell and is required for long-term facilitation in Aplysia. Neuron 18: 899-912

Morris, R.G. 1984. Developments of a water-maze procedure for studying spatial learning in the rat. J. Neurosci. Methods 11: 47-60.

Morris, R.G., Garrud, P., Rawlins, J.N., and O'Keefe, J. 1982. Place navigation impaired in rats with hippocampal lesions. Nature 297: 681-683

Nagahara, A.H., Otto, T., and Gallagher, M. 1995. Entorhinal-perirhinal lesions impair performance of rats on two versions of place learning in the Morris water maze. Behav. Neurosci. 109: 3-9.

O'Keefe, J., Nadel, L., Keightley, S., and Kill, D. 1975. Fornix lesions selectively abolish place learning in the rat. Exp. Neurol. 48: 152-166.

Olton, D.S., Walker, J.A., and Gage, F.H. 1978. Hippocampal connections and spatial discrimination. Brain Res. 139: 295-308.
Oswald, C.J. and Good, M. 2000. The effects of combined lesions of the subicular complex and the entorhinal cortex on two forms of spatial navigation in the water maze. Behav. Neurosci. 114: 211-217.

Paxinos, G. and Watson, C. 1997. The rat brain in stereotaxic coordinates. Academic Press, Inc., San Diego, CA.

Payne, D.M., Rossomando, A.J., Martino, P., Erickson, A.K., Her, J.H., Shabanowitz, J., Hunt, D.F., Weber, M.J., and Sturgill, T.W. 1991 Identification of the regulatory phosphorylation sites in pp42/ mitogen-activated protein kinase (MAP kinase). EMBO J. 10: 885-892.

Pouzet, B., Welzl, H., Gubler, M.K., Broersen, L., Veenman, C.L., Feldon, J., Rawlins, J.N., and Yee, B.K. 1999. The effects of NMDA-induced retrohippocampal lesions on performance of four spatial memory tasks known to be sensitive to hippocampal damage in the rat. Eur. J. Neurosci. 11: 123-140.

Press, G.A., Amaral, D.G., and Squire, L.R. 1989. Hippocampal abnormalities in amnesic patients revealed by high-resolution magnetic resonance imaging. Nature 341: 54-57.

Quirk, G.J., Muller, R.U., Kubie, J.L., and Ranck, Jr., J.B., 1992. The positional firing properties of medial entorhinal neurons: description and comparison with hippocampal place cells. J. Neurosci. 12: $1945-1963$.

Schafe, G.E., Nadel, N.V., Sullivan, G.M., Harris, A., and LeDoux, J.E. 1999. Memory consolidation for contextual and auditory fear conditioning is dependent on protein synthesis, PKA, and MAP kinase. Learn. Mem. 6: $97-110$.

Schafe, G.E., Atkins, C.M., Swank, M.W., Bauer, E.P., Sweatt, J.D., and LeDoux, J.E. 2000. Activation of ERK/MAP kinase in the amygdala is required for memory consolidation of pavlovian fear conditioning. $J$. Neurosci. 20: 8177-8187.

Schenk, F. and Morris, R.G. 1985. Dissociation between components of spatial memory in rats after recovery from the effects of retrohippocampal lesions. Exp. Brain Res. 58: 11-28.

Szapiro, G., Izquierdo, L.A., Alonso, M., Barros, D., Paratcha, G., Ardenghi, P., Pereira, P., Medina, J.H., and Izquierdo, I. 2000. Participation of hippocampal metabotropic glutamate receptors, protein kinase A and mitogen-activated protein kinases in memory retrieval. Neuroscience 99: 1-5.

Teather, L.A., Packard, M.G., and Bazan, N.G. 2002. Post-training cyclooxygenase-2 (COX-2) inhibition impairs memory consolidation. Learn. Mem. 9: 41-47.

Teng, E. and Squire, L.R. 1999. Memory for places learned long ago is intact after hippocampal damage. Nature 400: 675-677.

Walz, R., Roesler, R., Quevedo, J., Rockenbach, I.C., Amaral, O.B., Vianna M.R., Lenz, G., Medina, J.H., and Izquierdo, I. 1999. Dose-dependent impairment of inhibitory avoidance retention in rats by immediate post-training infusion of a mitogen-activated protein kinase kinase inhibitor into cortical structures. Behav. Brain Res. 105: 219-223.

Walz, R., Roesler, R., Quevedo, J., Sant'Anna, M.K., Madruga, M., Rodrigues, C., Gottfried, C., Medina, J.H., and Izquierdo, I. 2000. Time-dependent impairment of inhibitory avoidance retention in rats by posttraining infusion of a mitogen-activated protein kinase kinase inhibitor into cortical and limbic structures. Neurobiol. Learn. Mem. 73: 11-20.

Whishaw, I.Q. 1989. Dissociating performance and learning deficits on spatial navigation tasks in rats subjected to cholinergic muscarinic blockade. Brain Res. Bull. 23: 347-358.

Whishaw, I.Q. and Mittleman, G. 1986. Visits to starts, routes, and places by rats (Rattus norvegicus) in swimming pool navigation tasks. $J$. Comp Psychol. 100: 422-431.

Wu, G.Y., Deisseroth, K., and Tsien, R.W. 2001. Spaced stimuli stabilize MAPK pathway activation and its effects on dendritic morphology. Nat. Neurosci. 4: 151-158.

Zola-Morgan, S. and Squire, L.R. 1990. The primate hippocampal formation: Evidence for a time-limited role in memory storage. Science 250: 288-290.

Zola-Morgan, S., Squire, L.R., and Amaral, D.G. 1986. Human amnesia and the medial temporal region: Enduring memory impairment following a bilateral lesion limited to field CA1 of the hippocampus. J. Neurosci. 6: $2950-2967$.

Received March 14, 2002; accepted in revised form June 3, 2002.

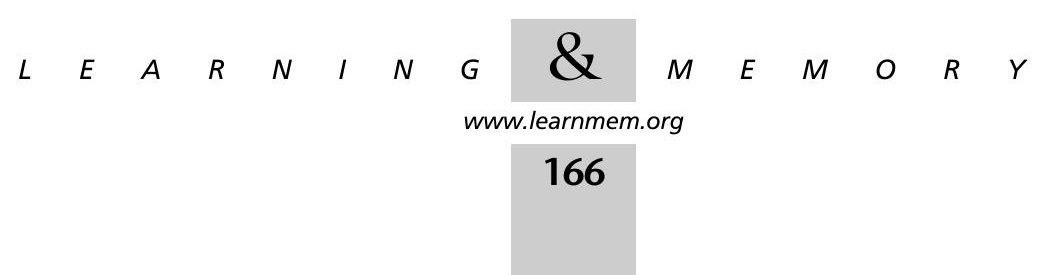




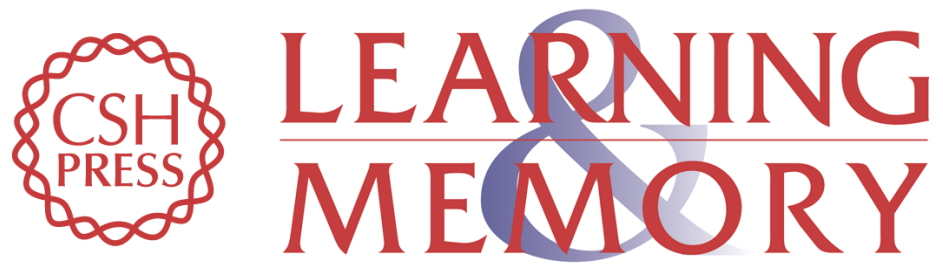

\section{Extracellular Signal-Regulated Kinase Activity in the Entorhinal Cortex Is Necessary for Long-Term Spatial Memory}

April E. Hebert and Pramod K. Dash

Learn. Mem. 2002, 9:

Access the most recent version at doi:10.1101/lm.48502

References This article cites 57 articles, 15 of which can be accessed free at: http://learnmem.cshlp.org/content/9/4/156.full.html\#ref-list-1

License

Email Alerting Receive free email alerts when new articles cite this article - sign up in the box at the Service top right corner of the article or click here. 